\title{
Suitability OF SERVICE ORIENTED ArChitecture For Solving GIS Problems
}

\author{
Mortaza Saleh ${ }^{1}$, Tahere Yaghoobi ${ }^{2}$ and Ahmad Faraahi ${ }^{3}$ \\ ${ }^{1}$ Department of Computer Engineering and Information Technology, Payame Noor \\ University, Tehran \\ Saleh.Mortaza@Gmail.com \\ ${ }^{2}$ Department of Computer Engineering and Information Technology, Payame Noor \\ University, Isfahan \\ T.Yaghoobi@pnu.ac.ir \\ ${ }^{3}$ Department of Computer Engineering and Information Technology, Payame Noor \\ University, Tehran \\ Afaraahi@pnu.ac.ir
}

\begin{abstract}
Nowadays spatial data is becoming as a key element for effective planning and decision making in all aspects of societies. Spatial data are those data which are related to the features on the ground. In this way, a Geographic Information System (GIS) is a system that captures, analyzes, and manages any spatially referenced data. This paper analyzes the architecture and main features of Geographic Information Systems and aims at discussing some important problems emerged in the research of applying GIS in the organizations. It focuses on some of them such as lack of interoperability, agility and business alignment. We explain that SOA as a service oriented software architecture model can support the transformation of geographic information software from "system and function" to "service and application" and as the best practice of the architectural concepts can increase business alignment in the enterprise applications.
\end{abstract}

\section{KEYWORDS}

Geographic Information System (GIS); Service Oriented Architecture (SOA); Spatial Data; Service; Enterprise GIS; Desktop GIS; Distributed System; Centralized System.

\section{INTRODUCTION}

An attention to location, spatial interaction, spatial structure and spatial processes lies at the heart of research in the social sciences. Spatial data are the lifeblood of an emerging and exciting computer mapping technologies know as Geographic Information Systems or GIS. A Geographic Information System integrates software, hardware, and data for managing, capturing, analyzing, and displaying all forms of geographically referenced information and allows us to view, understand, question, interpret, and visualize data in many ways that reveal relationships, patterns, and trends in the form of maps, globes, reports, and charts.

DOI : 10.5121/ijait.2012.2201 
Generally, a GIS is similar to a puzzle; Locations in this information system, such as Hospitals, Gas Stations and etc. are the pieces of this puzzle that can integrate together and make an exacted plan of a region. GIS technology enables organizations of all sizes in both the public and private sectors to take advantages of their geographic data.

The major opportunity for GIS for an organization is to create an "Enterprise GIS" solution where data, information and knowledge can be shared and flow freely throughout the enterprise and potentially to the general public. But lack of interoperability and inefficient data exchange between internal components of a GIS-based organization, has been a major impediment to the efficient access and communication of its structure. Efficient data sharing and software interoperability play a crucial role in supporting efficient data access and retrieval, which in turn is important to support efficient operations and cost-effective decision making processes at all levels of an organization. This deficiency is led to some other problems such as lack of business alignment and agility. We propose Service Oriented Architecture as the best practice of the architectural concepts for increasing business alignment and interoperability in the enterprise applications.

Despite management's desire to better align business and IT for over two decades, this goal remains elusive. Recently, Service Oriented Architecture has been proposed as a mechanism to facilitate alignment of IT with business requirements that are changing at an ever increasing rate because of its ability to engender a higher level of IT infrastructure flexibility [7, 10]. Service Oriented Architecture is a powerful solution to employ legacy systems, integration, extension and overall, deployment in business processes.

Although SOA is still in its infant stages [10] it has been advocated as an approach for building systems that enhances IT's ability to efficiently and effectively respond to the rapidly changing business environment and enables organizations to respond to these changes in a timely manner [7]. This architecture has attracted considerable attention among information technology practitioners due to its potential to address alignment of IT with business requirements. In this paper we explain that using Service Oriented Architecture specifications in GIS structure can overcome some of its problems such as lack of interoperability, business alignment and agility.

This paper is organized as follows: the background of research problem is reviewed in section 2 . Section 3 analyzes the connotation, model structure and main features of Geographic Information Systems. Section 4 is focused on Service Oriented Architecture and its general structure. In section 5 we introduce the features of a service-oriented GIS structure. A conclusion closes the body of this paper.

\section{BACKGROUND}

Recent approaches in enterprise business integration, in search of simplified processes are mostly driven by the emergence of the Service Oriented Architectures which are focused on an architectural style to design applications based on a collection of best practices, principles, interfaces, and patterns related to the central concept of services [18]. Because SOA is a type of enterprise architecture, it begins with the needs of the enterprise. However, the difference between SOA and other approaches to enterprise architecture is in the business agility as an ability to respond quickly and efficiently to change for competitive advantage. Chen and Lu, using SOA concepts proposed an enterprise application integration and business agility schema centered as business process management (BPM) and finally achieved the business agility [6]. On the other hand, business alignment has been studied extensively in the IS literature. In many cases, SOA has been considered as a means for alignment although it has been approached widely. For example, Yoon and Carter perceived SOA as an IT strategy, where it requires 
extremely high levels of business alignment to achieve benefits [29] or Jing and his colleagues presented an evaluation method for the services in SOA to promote business alignment and implemented this method in a distributed web application tool [12].

\section{GEOGRAPHIC INFORMATION SYSTEM}

A Geographic Information System is a computer system for assembling, storing, manipulating, and displaying data which contains physical locations of features and information about those features (attribute data). It considers as an exciting and fast growing field with a broad range of applications. This technology has emerged in the latter part of the twentieth century as an integrative information technology.

Generally, a GIS includes three types of capabilities; it includes database management capabilities for collecting and storing large amounts of geospatial data, together with spatial analysis capabilities to investigate geospatial relationships among the entities represented by that data, plus map display capabilities to portray the geospatial relationships in two and three dimensional map form.

We can list the benefits of GIS generally into five basic categories:

- Better decision making

- Better displaying and sensing the spatial data

- Improved communication

- Better geographic information record keeping

- Managing geographically

- Cost savings resulting from greater efficiency

\subsection{Storage of Spatial Data}

Establishing a well designed smart database is of crucial importance for data management to utilize its capabilities. According to the research results, as the concept and structure of object orienting are very close to the real world, it can solve many problems in more realistic ways and with more appropriate solutions.

Recently developing the subject of GIS is not exception and some of its concepts can coincide with those of object orienting to some extent. Geodatabases as GIS database have two major responsibilities that they are maintenance and management of data. For this purpose, geometric features with binary form and logical relationship are storied. Attribute data and its pertinent relations are also saved $[16,19]$.

In order to implement a database like the above mentioned ones, at the beginning, for every spatial entity and its attributed data, data resource including documents, plans, digital files, and etc. must be identified and based on them logical and physical model (real world model or data model) of database must be designed. Then, the process of changing the data from the data resources to the database must take place. The mentioned database can be implemented on different platforms/environments. Furthermore, it is easily generalizable to the relational database [19].

Based on the findings nowadays, those databases which are subcategory of Geographic Information Systems can function in one of the following three ways: 


\subsubsection{Personal GeOdatabase}

In personal Geodatabases, spatial data and attribute data are generally saved and restored in MSACCESS databases. In this type of database only one user can be connected at the same time. Furthermore, these types of databases are not able to store the spatial data with more than 2 GB capacity. These features show that personal Geodatabase is not appropriate for using in the organizations [19].

\subsubsection{File GEODATABASE}

In these databases, an excessive amount of spatial data and attribute data can be stored and applied simultaneously which this amount can be increased up to $1 \mathrm{TR}$. But the notable feature of these databases is their inability in multi user editing. Although these databases are not qualified to be considered as one of the best databases, they have more advantages in comparison with the above mentioned ones (Personal Geodatabase) [19]. However, this type of database is not suitable for use in the organizations.

\subsubsection{ENTERPRISE GEODATABASE}

These types of databases have overcome the mentioned drawbacks and apart from having all these metrics, they have the advantage of multi user editing as well. It worth mentioning that this type of databases which has also the general name of GIS database, benefits from some advantages such as historical archiving and versioning. Oracle, SQL server, DB2, Informix, and etc. are some examples for these databases. Table1 illustrates some of the main differences among the mentioned databases [13].

Utilizing versioning capability in multi user editing in databases, contributes to the acceleration of processes and also makes them easier. Data editing is a complicated process which demands substantial time and money. This developed editing process which can include plenty of short transactions is known as long transaction. Nowadays versioning technique provides the users with concurrent information editing.

Table 1. Comparison among three types of databases

\begin{tabular}{|l|c|c|c|}
\hline Darameters Types & $\begin{array}{c}\text { Personal } \\
\text { GeoDatabase }\end{array}$ & $\begin{array}{c}\text { File } \\
\text { GeoDatabase }\end{array}$ & $\begin{array}{c}\text { Enterprise } \\
\text { GeoDatabase }\end{array}$ \\
\hline Storage Format & Microsoft Access & Folder of Binary Files & DBMS \\
\hline Storage Capacity & 2 GB & 1 TB per Table & Depends on Edition \\
\hline Supported OS & Windows & Any Platform & Depends on Edition \\
\hline Number of Users & $\begin{array}{c}\text { Single Editor } \\
\text { Multiple Readers }\end{array}$ & $\begin{array}{c}\text { Single Editor } \\
\text { Multiple Reader }\end{array}$ & $\begin{array}{c}\text { Multiple Editors \& } \\
\text { Readers }\end{array}$ \\
\hline
\end{tabular}

\subsection{ARCHITECTURES OF GIS}

In general, user, application, and data constitute three basic dimensions of GIS architecture. But due to the variety of elements and their great applicability, other types of architecture such as centralized and distributed architectures stem from them. They are dealt with briefly in the following paragraphs. 
In the centralized architecture, web service application with centralized management and one way access to the data are used. Due to this characteristic, there is a great dependency to the program and the data in the network. On the other hand, they reduce traffic of local and distributed networks. In these systems two significant factors of operation and supporting, increase in local networks and decrease in regions. In general, requirements of the resources in the data centers reach minimum. Having centralized database and system management are the most prominent features of these systems. By using these systems we can also utilize desktop GIS architecture that in this architecture client/server relation is also possible. Figure 1 illustrates the architecture of these systems. Dependencies of the programs and the data are clearly depicted in this figure [9].

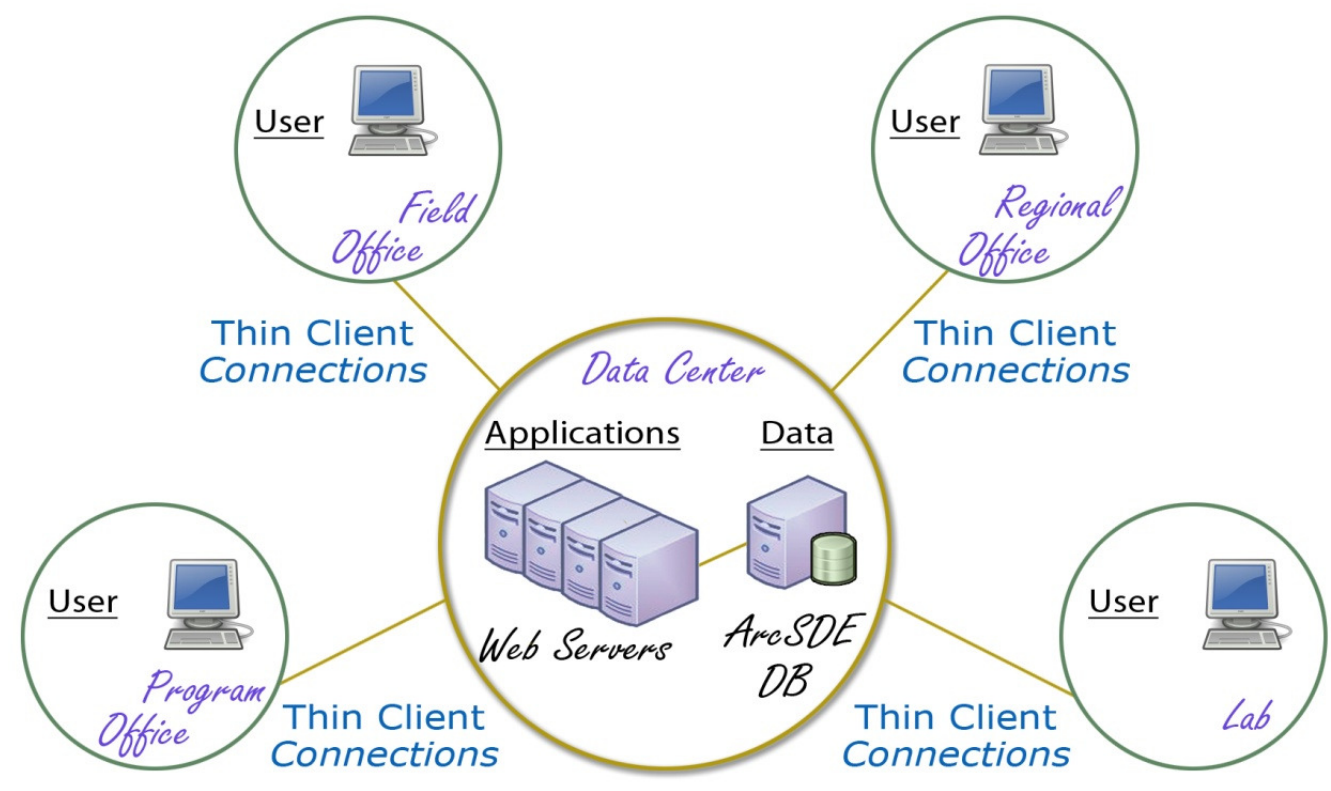

Figure 1. Centralized architecture of GIS [9]

In the distributed architecture, in order to have concurrence and integration of information in the databases and systems and by considering the structure, it is necessary to do replication of the data consecutively. This architecture consists of a wide group of centralized architecture which are related to gather in various ways and utilized the data and information based on their defined access level. In this architecture local networks are usually used as offline [9]. The mobile-GIS can also be exploited in these networks. In general, it is the most important merit of this architecture that the data and information are not geographically centralized in a special location. Consequently, it results in good quality of services, ease of accessibility, ease of information updating, integration, and awareness of the data and information and etc. Figure 2 illustrates this architecture [13].

Another type of architecture which can stem from these systems is Enterprise GIS architecture. Here, several architectures such as distributed and centralized are applied based on business enterprise. Nowadays, by recent progress of Information Technology, and advent of Service Oriented Architecture, most of the drawback of this architecture is overcome and its basic structure is strengthened as well [13]. Enterprise GIS architecture can be used for implementing Geographic Information Systems in official organizations. But this type of architecture, like other new system/architecture, has some disadvantages such as lack of interoperability, business 
alignment, and agility. These disadvantages decrease the output of the system and waste lot of time as well $[5,15]$. This matter encouraged us to recommend Service Oriented Architecture for solving these problems.

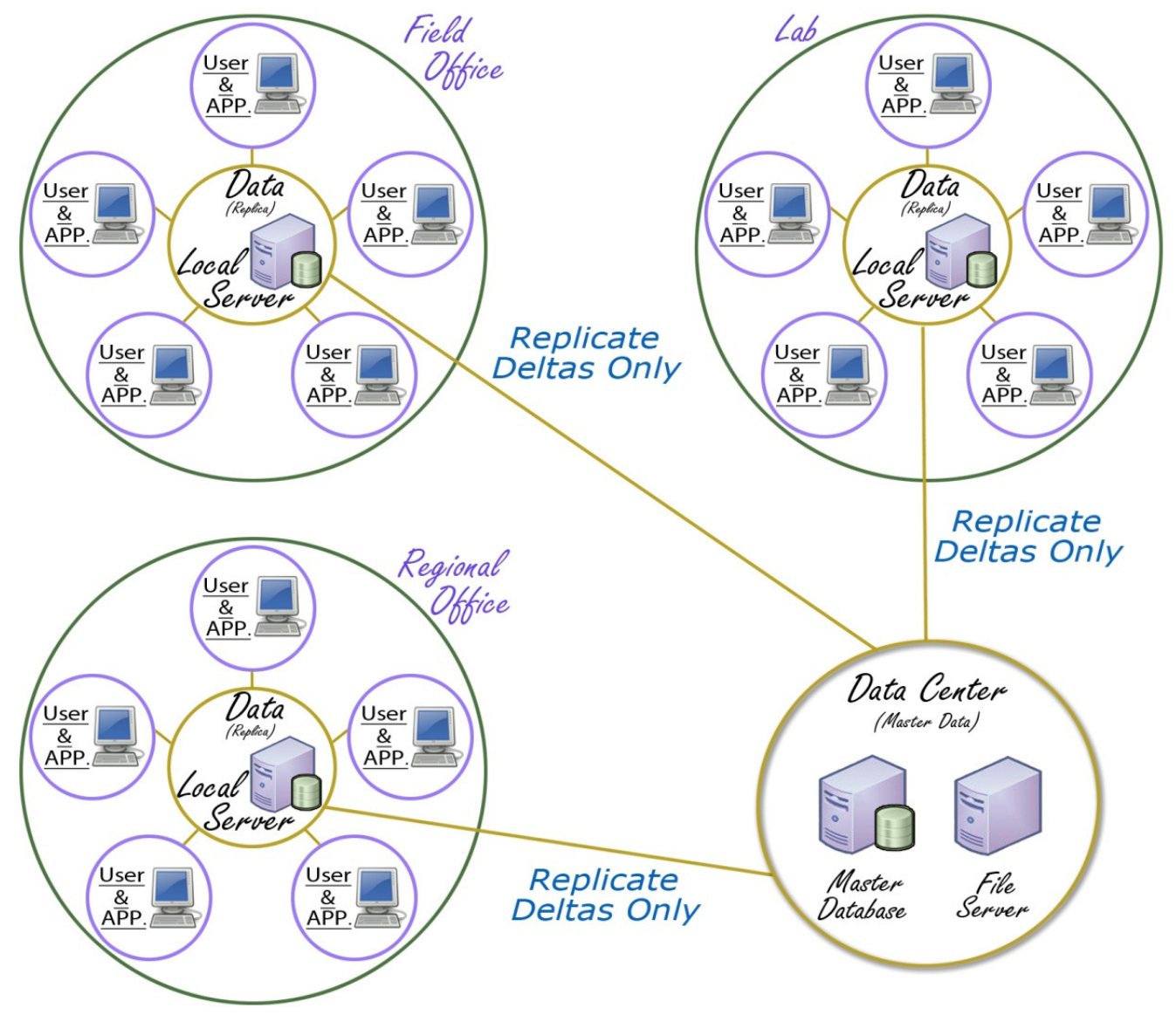

Figure 2. Distributed architecture of GIS [9]

\section{SERViCE Oriented ArChitecture}

\subsection{OVERVIEW OF SOA}

The basic idea of Service Oriented Architecture has received significant attention and concern from the community of software design and development. Service-orientation is a design paradigm to build computer software in the form of services. It provides a governing approach to automate business logic as distributed systems and has received a lot of attention since 2005. In this way, a comparative review between three software engineering approaches is shown in table $2[30]$.

In [3], Beg and his colleagues described "object oriented" approach as a kind of the earlier approaches to building IT systems that tended to directly use specific implementation environments to solve the business problems. In [27] Chen and his colleagues proposed the "component-based" approach as another common development paradigm which extends object- 
oriented with components, whose grain is larger than objects. Both of them can be well supported by middleware standards such as .NET and CORBA [30]. Service-orientation inherits a number of principles from earlier paradigms including object-orientation, component-based software engineering and open distributed processing. "SOA" as the third approach can be considered as an approach to building IT systems in which business services are the key organizing principle used to align IT systems with the needs of the business.

Table 2. Comparison among Object-oriented, Component-based, and SOA [30]

\begin{tabular}{|c|c|c|c|}
\hline Parameter & Object Oriented & Component-based & $\begin{array}{c}\text { Service Oriented } \\
\text { Architecture }\end{array}$ \\
\hline $\begin{array}{c}\text { Platform } \\
\text { Independence }\end{array}$ & Object & Component & Service \\
\hline Design Purpose & $\begin{array}{c}\text { Implementation } \\
\text { Requirement }\end{array}$ & $\begin{array}{c}\text { Implementation } \\
\text { Requirement }\end{array}$ & Adapt to Changing \\
\hline Granularity & Fine-grained & Fine-grained & Coarse-grained \\
\hline Reusability & Application-Specific & $\begin{array}{c}\text { Reusable across } \\
\text { application }\end{array}$ & $\begin{array}{c}\text { Reusable across } \\
\text { domains }\end{array}$ \\
\hline $\begin{array}{c}\text { Application } \\
\text { Interface }\end{array}$ & $\begin{array}{c}\text { Specific to this } \\
\text { object/class(e.g. IDL) }\end{array}$ & $\begin{array}{c}\text { Interface separated } \\
\text { from components }\end{array}$ & $\begin{array}{c}\text { Specific to service } \\
\text { description protocol } \\
\text { specific(e.g. WSDL) }\end{array}$ \\
\hline Addressing & $\begin{array}{c}\text { Routed to unique } \\
\text { object instance }\end{array}$ & Routed to component & $\begin{array}{c}\text { One endpoint address } \\
\text { per service }\end{array}$ \\
\hline
\end{tabular}

These three approaches provide reusability but with different degrees. Component-based approach provides enhanced reusability through components. A major hindrance in taking advantage of existing functions is the uniqueness of specific applications and systems. In this way, developed solutions in different enterprises have unique characteristics.

They are coded in different languages or programmed with different interfaces and protocols and run in different environments. Object-oriented approach and component-based solutions cannot solve this problem. SOA even extends the component-based and object-oriented reusability with service paradigm. System functions can be dramatically easier to access as a service in SOA and so it is much simpler to integrate applications and systems. Granularity refers to the scope of functionality. Fine grained services might be services that provide a small amount of businessprocess usefulness [30].

What can be seen from the comparison is that fundamental models of object-oriented approach and component-based approach can also be applied in Service Oriented Architecture. For example, components in component-based solutions can be wrapped and used in service. SOA can also improve integration, intrinsic interoperation, inherent reuse and organizational agility, streamline architectures and solutions, and leverage the legacy investment [30]. Abstraction level and granularity degree between these approaches is shown in Figure 3. 


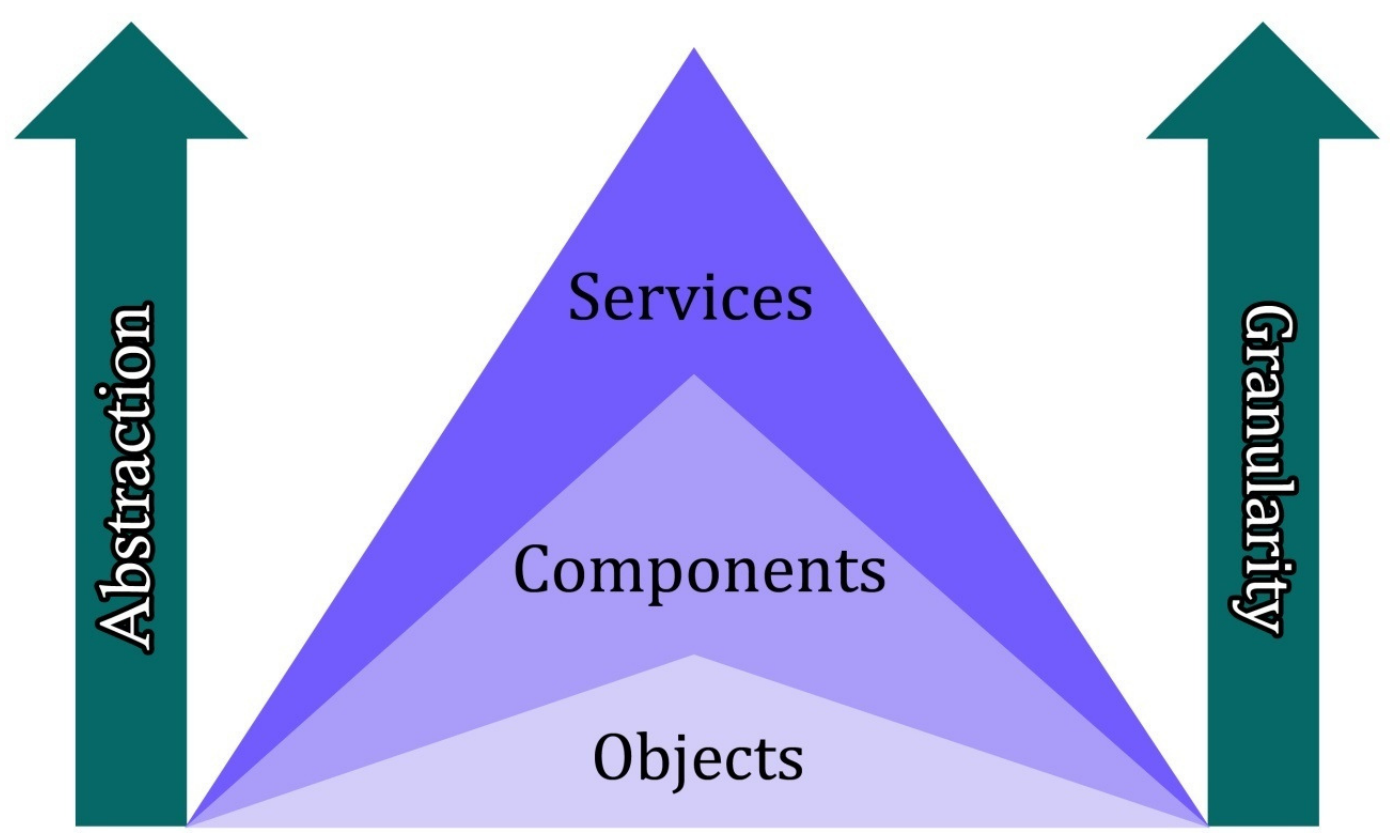

Figure 3. Abstraction level and Granularity degree between three mentioned approaches [24]

\subsection{SERVice Oriented ArChitecture Advantages}

As described above, Service Oriented Architecture is a very popular architecture paradigm for systems development and integration that provides a comprehensive and agile way to integrate information systems and businesses processes. This architecture consists of three elements: a "service provider" that publishes and maintains a service, a "service consumer" that uses the service, and a "service registry "that allows service discovery by prospective consumers $[11,17]$.

In this definition, service is a self-contained software module that performs a predetermined task and consider as the basic building block of SOA. In other words, a service is a function that is well-defined, self-contained, does not depend on the context or state of other services. Firstly we say that Services in SOA are loosely coupled. This advantage allows us to replace or change components, without having to make reflective changes to other components in the systems. This means that businesses can change their business systems as needed, with much more agility than if the architecture/systems were more tightly coupled. Loose coupling nature makes services independent and thus any user of service need not be concerned with how the service is implemented and must only be aware of how they operate and how they ought to be used.

Regarding to this concept, an ideal service in SOA has the following characteristics [4]:

- It is self-contained. The service is highly modular and can be independently deployed.

- It is a distributed component. The service is available over the network and accessible through a name or locator other than the absolute network address.

- It has a published interface. Users of the service only need to see the interface and can be oblivious to implementation details.

- It stresses interoperability. Service users and providers can use different implementation languages and platforms. 
International Journal of Advanced Information Technology (IJAIT) Vol. 2, No.2, April 2012

- It is discoverable. A special directory service allows the service to be registered, so users can look it up.

- It is dynamically bound. A service user does not need to have the service implementation available at build time; the service is located and bound at runtime.

Business process management is the other key advantage of SOA. Business processes may consume and orchestrate some services to achieve the desired functionality. Thus, new business processes can be constructed by using existing services. This is a major goal of serviceorientation; establish native interoperability within services in order to reduce the need for integration. In other words, integration as an old concept begins to fade within service-oriented environments. Also SOA is very much geared toward establishing wide-spread organizational agility. Increasing organizational agility is very attractive to corporations. When serviceorientation is applied throughout an enterprise, it results in the creation of services that are highly standardized and reusable and therefore agnostic to parent business processes and specific application environments.

\section{SERVICE-ORIENTED GIS}

As mentioned in previous sections, despite all the above advantages of a geographic information system, it is faced with some problems such as lack of interoperability, business alignment, and agility in some organizational structures. These disadvantages decrease the output of the system/architecture and waste lot of time as well $[5,15]$. On the other hand, when an organization offers and receives services, it becomes necessary for that organization to develop a strategic platform of technology which can enable all system of inside / outside the organization to offer and receive service and also satisfy the demand of users $[2,26]$.

We explained that Service-Oriented concepts and its advantages can reduce some organizations drawbacks and it can implement in many different network environments. We introduced the business process management as a key advantage of SOA and said that establishing native interoperability within services in SOA structure can solve the first mentioned problem of GIS; Lack of interoperability. As a result, in order to overcome the drawbacks of GIS, we can use SOA structure for Geographic Information Systems. Generally, the services in GIS can classify in three categories:

- Data Services: These types of services are tightly coupled with specific data sets and offer access to customized portions of that data. Web Feature Service (WFS), Web Mapping Service (WMS) and Web Coverage Service (WCS) can be considered in this group. WFS provides geospatial feature data encoded in Geography Markup Language (GML). WMS produces maps as two-dimensional visual portrayals of geospatial data. WCS provides access to un-rendered geospatial information.

- Processing Services: These types of services provide operations for processing or transforming data in a manner determined by user-specific parameters. They provide generic processing functions such as projection and coordinate conversion, rasterization and vectorization. Coverage Portrayal Service (CPS), Coordinate Transformation Service (CTS), and even WMS can be considered in this group.

- Registry or Catalog Service: These types of services allow users and applications to classify, register, describe, search, maintain, and access information about Web Services. Web Registry Service and Web Catalog Service are considered in this group. 
International Journal of Advanced Information Technology (IJAIT) Vol. 2, No.2, April 2012

As discussed in [21], we can divide these services into more detailed sections. In our previous study [21], we proposed a service-oriented GIS platform that supported GIS functionalities along with enterprise viewpoints in a proper manner. However, SOA specifications such as loose coupling, reusability, abstraction, agility, and etc., can spread to organizations that using geographic information systems and increase their efficiency.

\section{CONCLUSION}

Geographic Information Systems are utilized for collecting and analyzing all information which has something to do with geographical situations. This information can be in the form of maps, tables of data, or lists of names or addresses. Due to the enormous capacity of this type of data, dealing with them is both difficult and time consuming. Hence, it is necessary to use more updated and new information which function according to some spatial data. These systems are named Geographic Information System. By considering their wide application and in order to do multi user editing of information, inquiry, and analyzing enormous data either in the form of spatial or attribute data, a special type of databases known as Geodatabase plays the role. Geodatabases consists of several types such as Personal, File and Enterprise Geodatabases. Enterprise Geodatabase enables the users to use spatial data and analyze the data based on them for organizations.

Despite all the above advantages, Geographic Information Systems suffer from some drawbacks such as lack of interoperability, business alignment and agility. The present study, introduced Service Oriented Architecture as a perfect solution for the mentioned drawbacks. Independence of services and having weak connections among them, are the most conspicuous features of Service Oriented Architecture which enable this architecture to overcome the mentioned drawbacks of Geographic Information System.

\section{REFERENCES}

[1] Amini A, Riahi H, Karimzadegan D, Vahdat D; "GIS Software Architecture Based on SOA Concept and OGC Standards", 2nd International Conference on Computer Engineering and Technology (ICCET), Vol. 4, pp. 424-431, 2010.

[2] Anand S, Padmanabhuni S, Ganesh J; "Perspectives on Service Oriented Architecture", International Conference on Services Computing, Vol. 2, Florida, pp. 104-119, 2005.

[3] Beg J, Shunmugam M; "An object oriented planner for inspection of prismatic parts - OOPIPP", International Journal of Advanced Manufacturing Technology, Vol. 12, No. 12, pp. 905-916, 2002.

[4] Bianco P, Kotermanski R, Merson P; "Evaluating a Service-Oriented Architecture", software Engineering Institute, 2007.

[5] Chen H; "Towards Service Engineering: Service Orientation and Business-IT Alignment", 41st Hawaii International Conference on System Sciences (HICSS), pp. 1-10, 2008.

[6] Chen L, Lu X; "Achieving Business Agility by Integrating SOA and BPM Technology", International Forum on Information Technology and Applications, Vol. 1, pp. 334-337, 2009.

[7] Choi J, Ramamurthy K; "Service-Oriented Architecture and IT-Business Alignment", International Conference on Industrial Engineering and Operations Management Kuala Lumpur, Malaysia, pp. 480485, 2011.

[8] Do-Hyun K, Kwang-Soo K, Haeock C, Jong-Hun L; "The Design and Implementation of Open GIS Service Component", International Geoscience and Remote Sensing Symposium, Vol. 4, pp. 19221924, 2001.

[9] Fabling Ty; "Enterprise GIS Architecture", Federal User Conference ESRI Enterprise Consulting Group, pp. 1-53, 2008.

[10] Hirschheim R, Welke R, Schwarz A; "Service-oriented architecture: myths, realities, and a maturity model", MIS Quarterly Executive, Vol. 9, pp. 37-48, 2010.

[11] Huhns M, Singh M; "Service-oriented computing: Key concepts and principles", IEEE Internet Computing, Vol. 9, No. 1, pp. 75-81, 2005. 
International Journal of Advanced Information Technology (IJAIT) Vol. 2, No.2, April 2012

[12] Jing W, Yeong S, Yupei X; "Service Evaluation in SOA: Toward Business/IT Alignment", 10th ACIS International Conference on Software Engineering, Artificial Intelligences, Networking and Parallel/Distributed Computing, pp. 310-315, 2009.

[13] Joseph K; "Map Analysis: Understanding Spatial Patterns and Relationships", Denver: GeoTec Media 2007, 2007.

[14] Lu X; "An Investigation on Service-Oriented Architecture for Constructing Distributed Web GIS Application", International Conference on Services Computing (SCC'05), Vol. 1, pp. 191-197, 2005.

[15] Ma S, Li M, Du W; "Service Composition for GIS", Congress on Services 2008, pp. 168-175, 2008.

[16] Murphy J, Zwicker C; "Geodatabase Essentials Part I", Esri International User Conference, San Diego, CA, 2010.

[17] Papazoglou M; "Service-oriented computing: Concepts, characteristics and directions", Proceedings of the Fourth International Conference on Web Information Systems Engineering, pp. 3-12, 2003.

[18] Papazoglou M, Heuvel W; "Service oriented architectures: approaches, technologies and research issues", In VLDB Journal, Vol. 16, pp. 389-415, 2007.

[19] Pierce B, MacDougall G; "Geodatabase Essentials Part II", Esri International User Conference, San Diego, CA, 2010.

[20] Rui-sheng J, Yan J, Hong-mei Y, Xi-juan W; "Research on Distributed GIS Process Modeling and Integration", International Symposium on IT in Medicine and Education, pp. 33-38, 2008.

[21] Saleh M, Yaghoobi T, Faraahi A; "A Combinational Approach of GIS and SOA for performance improvement of organization", International Journal of Web \& Semantic Technology, Vol.3, No.1, pp. 11-22, 2012.

[22] Shengjun X, Liang Z; "Developing GIS Software with Component Technic", International Symposium on Intelligent Information Technology Application Works, pp. 726-728, 2008.

[23] Shujun D, Liang L, Chengqi C; "Research on Geographical Information Service Based on SOA", International Conference on Automation and Logistics, Qingdao, pp. 2977-2981, 2008.

[24] Sprott D, Wilkes L; "Understanding Service-Oriented Architecture", CBDI Journal, 2004.

[25] Tan X, Feng X; "Design of GIS Component Software with Example", First International Conference on Intelligent Networks and Intelligent Systems, pp. 367-370, 2008.

[26] Valipour M, Amirzafari B, Niki Maleki K, Daneshpour N; "A Brief Survey of Software Architecture Concepts and Service Oriented Architecture", 2nd International Conference on Computer Science and Information Technology(ICCSIT), pp. 34-38, 2009.

[27] Wu X, Chen J, Li R, Li F; "Web-based remote monitoring and fault diagnosis system", International Journal of Advanced Manufacturing Technology, Vol. 28, pp. 162-175, 2006.

[28] Xiang F, Ling G, Jin Y; "User-driven GIS Software Reuse Solution Based on SOA and Web2.0 Concept", 2nd International Conference on Computer Science and Information Technology(ICCSIT), pp. 5-9, 2009.

[29] Yoon T, Carter P; "Investigating the Antecedents and Benefits of SOA Implementation: A Multi-Case Study Approach", Americas Conference on Information Systems (AMCIS), pp. 1-12, 2007.

[30] Zhao F, Chen J, Dong G, Guo L; "SOA-based remote condition monitoring and fault diagnosis system", The International Journal of Advanced Manufacturing Technology, Vol. 46, No. 9, pp. 11911200, 2009.

\section{Authors}

M. Saleh received his B.Sc degree in Computer Engineering from Payame Noor University, Iran in 2008. Currently he is pursuing his master degree in the Software Engineering in Payame Noor University, Tehran, Iran. His interests include Service Oriented Architecture, Information Systems, Security, and Coordination Problems.

Dr.T. Yaghoobi is an Assistant Professor at the Department of Computer and Information Technology Engineering in the Payame Noor University, Isfahan, Iran. She has received the PhD degree in Computer Sciences from Sheffield Hallam University, UK. Her main research interest is artificial intelligence.

Dr.A. Faraahi received the $\mathrm{PhD}$ degree in Computer Sciences from Bradford University. He has been working as a full-time faculty member, Assistant Professor and Head of Computer and Information Technology Department in the Payame Noor University. His research interests are programming especially that of educational systems. 